6-2015

Which role do midwives and gynecologists have in smoking cessation in pregnant women?-A study in Flanders, Belgium

Katrien De Wilde

Inge Tency

Sarah Steckel

Marleen Temmerman

Hedwig Boudrez

See next page for additional authors

Follow this and additional works at: https://ecommons.aku.edu/eastafrica_fhs_mc_obstet_gynaecol

Part of the Obstetrics and Gynecology Commons, and the Women's Health Commons 


\section{Authors}

Katrien De Wilde, Inge Tency, Sarah Steckel, Marleen Temmerman, Hedwig Boudrez, and Lea Maes 


\title{
Which role do midwives and gynecologists have in smoking cessation in pregnant women? - A study in Flanders, Belgium
}

\author{
Katrien De Wilde ${ }^{\mathrm{a}, *}$, Inge Tency ${ }^{a}$, Sarah Steckel ${ }^{a}$, Marleen Temmerman ${ }^{\mathrm{b}}$, \\ Hedwig Boudrez ${ }^{c}$, Lea Maes ${ }^{\mathrm{d}}$ \\ a Odisee University College, Hospitaalstraat 23, Sint-Niklaas 9100, Belgium \\ ${ }^{\mathrm{b}}$ Department of Obstetrics and Gynaecology, Faculty of Medicine and Health Sciences, Ghent University, De Pintelaan 185, Ghent 9000, Belgium \\ ' Stop-smoking Clinic, Ghent University Hospital, De Pintelaan 185, Ghent 9000, Belgium \\ ${ }^{\mathrm{d}}$ Department of Public Health, Faculty of Medicine and Health Sciences, Ghent University, De Pintelaan 185, Ghent 9000, Belgium
}

\section{A R T I C L E I N F O}

\section{Article history:}

Received 22 August 2014

Revised 20 December 2014

Accepted 30 December 2014

\section{Keywords:}

Smoking cessation

Pregnancy

Midwives

Gynecologists

Counseling

\begin{abstract}
A B S T R A C T
Objectives: The objectives of our study were (1) to explore knowledge, beliefs and practice among midwives and gynecologists concerning a smoking cessation policy for pregnant women and their partners and (2) to examine if midwives and gynecologists do have a role in smoking cessation in pregnant women. Method: We performed a qualitative study using semi-structured interviews with nine midwives and eight gynecologists. Data were analyzed using deductive content analysis, based on the 5 A's framework (Ask-Advise-Assess-Assist-Arrange).

Results: The national smoking cessation policy seemed to be insufficiently known. "Ask" and "Advise" were part of a standard prenatal consultation, the next three steps were rarely implemented. Participants had a negative image of "the smoking pregnant woman": a low educated woman with a smoking partner and "bad examples" in their history. Reported barriers were fear of provoking resistance and lack of time and communication skills regarding smoking cessation.

Conclusions: These findings suggest that training in communication skills and dealing with resistance should be offered, i.e. by using motivational interviewing. It could be considered that a trained midwife or tobaccologist is part of an obstetrical team or that the AAR-method (Ask-Advise-Refer) is used instead of the 5 A's framework.
\end{abstract}

(C) 2014 Elsevier B.V. All rights reserved.

\section{Introduction}

Smoking during pregnancy is associated with a number of fetal and maternal health risks, such as stillbirth, low birth weight, preterm delivery, placenta pathology and sudden infant death syndrome (SIDS) $[1,2]$.

The preconceptional and prenatal period is considered as the ideal teaching moment for smoking cessation counseling [3]. However, a number of studies identified personal and organizational barriers to providing effective smoking cessation advice: lack of motivation or interest to work with clients on this subject [4], absence of clear guidelines [4], lack of knowledge where and to whom to refer to [5], fear of providing advice with impact on the quality of their relationship [6], competing priorities in prenatal care such as acute obstetric complications [7], underestimating the risks of smoking during pregnancy [8], absence of trust [9], low

\footnotetext{
* Corresponding author. Odisee University College, Hospitaalstraat 23, Sint-Niklaas 9100, Belgium. Tel.: +32 (0)3 7764348

E-mail address: Katrien.dewilde@odisee.be (K. De Wilde).
}

chances of success $[10,11]$ and in particular lack of time $[5,6,8,12]$ and specific training needs $[4,6,7,10,12]$. As a consequence, health care providers feel incompetent to give smoking cessation advice.

The American College of Obstetricians and Gynecologists recommends use of the $5 \mathrm{~A}$ 's, an evidence-based, clinical practice guideline for smoking cessation. The 5 A's remind health care providers to: (1) ask the client about her smoking status at every prenatal visit; (2) advise her to stop smoking in a clear, strong and personalized way; (3) assess her willingness to stop smoking and motivations to quit, if she is not willing to make a quit attempt at the present time, then try to increase motivation to quit at a later time; (4) assist the client to stop smoking by providing brief counseling, prescription of pharmacotherapy, and provision of written self-help material; and (5) arrange specific follow-up to prevent the client from relapsing to tobacco use and enroll her in a local smoking cessation program [3].

Motivational interviewing (MI) is a style of patient-centered counseling developed to facilitate change in health-related behavior. The core principle of the approach is negotiation rather than conflict [13]. MI is widely used to help people make an attempt to change their harmful behavior and appears to be modestly successful in 
promoting smoking cessation, compared to standard care or brief interventions [14]. Motivation may fluctuate over time or from one situation to another, and can be influenced to change in a particular direction. Lack of motivation or resistance to change is seen as something that is open to change. The main focus of MI is facilitating behavior change by helping people to explore and resolve their ambivalence about behavior change. Adopting a victimblaming, aggressive and/or confrontational style as in traditional approaches, is likely to produce negative responses like arguing, which may be interpreted by the health care provider as denial or resistance [14].

In Flanders (Northern Belgium), prenatal care is mostly provided by a gynecologist or a midwife and sometimes by a general practitioner. As such, these health care providers are well-placed to deliver smoking cessation advice during pregnancy. In 2011 the prevalence of smoking during pregnancy in Flanders was 12.3\% [15]. Since 2004 the Belgian government implements a national smoking cessation policy. Smoking pregnant women attending at least eight consultations with a tobaccologist receive a reimbursement of $€ 30$ for every consult with a maximum of $€ 240$. Smoking partners of pregnant women receive $€ 30$ for the first and $€ 20$ for the following seven consultations. Folders and flyers promoting this reimbursement were distributed among midwives and gynecologists by mail. From January 2006 to June 2009 the government only received 133 requests for reimbursement [16]. The lack of success of this policy might be explained partly by a lack of awareness among health care providers, resulting in few referrals to tobaccologists. Furthermore, women continuing smoking during pregnancy might be a low motivated group, not yet prepared to invest in smoking cessation consultations and who are hard to reach with smoking cessation information and support. The national policy, originally restricted to pregnant women and their partner, was extended in October of 2009: smoking cessation reimbursement has been available since then for each counseling session (individually or in group) by a tobaccologist or a physician.

Since gynecologists perform most prenatal consultations and since there is an increasing percentage of women consulting a midwife [17-19], our study population was limited to gynecologists and midwives. The objectives of our study were (1) to explore knowledge, beliefs and practice among midwives and gynecologists concerning smoking cessation several years after the implementation of a smoking cessation policy for pregnant women and their partners and (2) to examine if midwives and gynecologists in Flanders do have a role in smoking cessation in pregnant women.

\section{Methods}

Design

A qualitative study using semi-structured interviews was conducted in order to describe and analyze midwives' and gynecologists' experiences with giving smoking cessation advice during pregnancy. Areas of interest included in the interview guide were based on the authors' clinical expertise regarding prenatal consultations and the $5 A^{\prime}$ 's framework.

\section{Participants}

Purposive sampling was used to select eligible participants, representing both occupational groups (midwives and gynecologists). In order to be included participants had to perform prenatal consultations. Years of experience in prenatal care were taken into account ( $\leq 10$ years and $>10$ years). We expected to reach data saturation by recruiting three to five participants in each cell of the sampling matrix, with a minimum of twelve and a maximum of twenty participants. When data saturation was not reached extra interviews would be performed.

In Flanders there were 467 registered gynecologists and 198 registered independent midwives at the time of sampling (2008). First, a list of gynecologists was obtained from the Flemish Organisation for Obstetrics and Gynaecology. All 467 registered Flemish gynecologists received an invitation to participate in the interview (April 2008). Two weeks later a reminder was sent to the non-responders. Five letters returned address unknown. Seventeen gynecologists replied: two had no prenatal consultations, four planned to retire within the following months and eleven agreed to participate. Following further explanation by telephone, three gynecologists refused participation. Finally, in total eight gynecologists were interviewed, four with less than 10 years of experience in prenatal care, four with more than 10 years of experience.

Second, a list of registered independent midwives was obtained from the Flemish Organisation of Midwives. In total 198 midwives were invited to participate in the interview (June 2008). Two weeks later a reminder was sent. Eleven midwives replied and finally nine midwives agreed to be interviewed. Five midwives had less than 10 years of experience, four had more than 10 years of experience.

Recruitment was not continued, as data saturation and the objectives of the sampling matrix had been reached.

\section{Data collection}

Seventeen interviews were conducted by the first author between June 2008 and January 2010 and lasted between 23 and 61 minutes. One researcher performed all of the interviews, thus ensuring consistency throughout the data collection. All interviews, except one, took place at the midwife's or doctor's office.

Semi-structured face-to-face interviews were conducted using an interview guide with open-ended questions. The topics for the interview guide were partially inspired by the English questionnaire of Bull and Whitehead [12]. The questionnaire was translated into Dutch and two questions concerning knowledge about smoking cessation programmes for pregnant women were adapted to the Belgian situation. A gynecologist, a sociologist, two midwives, a psychologist-tobaccologist and an ethicist reviewed the interview guide in order to establish content validity. No additional items were added.

The final interview guide consisted of three main topics, with corresponding questions, regarding:

- Knowledge about risks of smoking during pregnancy, smoking cessation guidelines and interventions and the use of nicotine replacement therapy (NRT):

$\bigcirc$ Tell me what you know about the risks of smoking during pregnancy

$\bigcirc$ To which extent are you familiar with the national policy regarding "stoppen met roken (smoking cessation)"? What is the content of this policy?

$\bigcirc$ To which extent are you familiar with other interventions, campaigns, guidelines and their contents?

$\bigcirc$ Tell me what you know about the use of NRT during pregnancy.

- Beliefs about smoking and smoking pregnant women:

$\bigcirc$ To which extent do you agree with the following statement: "a pregnant woman is able to quit smoking"?

$\bigcirc$ What are the main reasons why women continue to smoke during pregnancy?

$\bigcirc$ Under which circumstances would it be better for a pregnant smoker to continue smoking rather than attempt to stop?

$\bigcirc$ In your opinion, what are effective interventions to promote smoking cessation for pregnant women? 
What is your opinion on influencing the decision of a pregnant woman to continue or to quit smoking?

To which extent do you agree with the following statement: "I am the right person to offer smoking cessation advice to pregnant women."

- Dealing with smoking and smoking cessation during prenatal consultation:

Tell me how you conduct a conversation with a pregnant smoker [note to interviewer: keep in mind: Ask, Advice, Assess, Assist and Arrange follow-up]

$\bigcirc$ If interested, what kind of smoking cessation training would you need or prefer?

Finally we asked participants about their work experience, training in smoking cessation counseling and their own smoking status.

\section{Ethical considerations}

The study was approved by the Ethical Committee of Ghent University Hospital. All interviews were audiotaped with permission from the participant. Written informed consent was obtained prior to the interview and confidentiality was assured. After completion of the study the tapes will be destroyed.

\section{Data analysis}

Data analysis was based on deductive content analysis. This method is used when the structure of analysis is operationalized on the basis of previous knowledge [20]. Analysis of the way participants handled smoking and smoking cessation during prenatal consultation was based on the 5 A's framework [3].

Members of the research team (KDW, KT) transcribed the recordings of each interview verbatim. The researchers checked the transcriptions with the recordings in order to gain accuracy. Transcripts were read several times to obtain a sense of the whole. A thorough reading of the transcripts was followed by the development of a categorization matrix based on the interview guide and the 5 A's framework (Table 1 ). Next, data were coded according to the categories [20]. Findings were discussed with all authors and consensus with regard to the reflections was reached.

\section{Results}

\section{Participant characteristics}

All participants were non-smokers at the time of the interview, two were ex-smokers. All participants, except two, were female. Three midwives attended a training in smoking cessation skills (Table 2). Participants came from different Flemish provinces.

\section{Themes}

All data could be categorized in the five themes of the categorization matrix. The last interviews confirmed the validity of these theme, no new themes emerged. Each theme includes quotes from the participants.

Theme 1: Basic knowledge regarding fetal and maternal risks associated with smoking during pregnancy

Basic knowledge is defined as the readily available knowledge participants have at the moment of the interview without having to do research about the topic. The most common risks of smoking reported by both occupational groups were intrauterine growth restriction, low birth weight, placental problems and sudden infant death syndrome.
Midwives spontaneously mentioned fetal or neonatal risk factors and were more uncertain about some risks, such as preeclampsia, hypertension and malformations. Midwives-teachers also knew the risk of stillbirth and fertility problems.

Gynecologists immediately made a distinction between neonatal and maternal risks. They mentioned such additional risks as fertility problems, early menopause, lung diseases, different forms of cancer, premature aging of the skin, an irritable or lazy baby and long term risks for the child such as negative influence on school results, addictive behavior and allergies. In their opinion, the risks of premature skin aging and fertility problems have a stronger effect on smoking cessation compared to a list of neonatal risks.

All participants were convinced that prevention is required because of the risks for mother and child. Smoking prevention as well as smoking cessation in general are considered to be important health issues. They believed that smoking cessation advice should start before pregnancy, preferably in high school, since smoking cessation can take several attempts and requires time, even more than the duration of a pregnancy. Sensitizing society by promoting non-smoking is important as well, according to the participants.

Theme 2: Specific knowledge regarding national smoking cessation guidelines and the use of nicotine replacement therapy (NRT)

In most cases, the specific knowledge regarding smoking cessation guidelines or interventions was limited. The precise requirements of the programme for reimbursement, such as the number of consultations or the amount of the repayment, were largely unknown. Half of the participants thought that the national policy provided free smoking cessation counseling.

The interviewed midwives had insufficient knowledge regarding the use of NRT in pregnancy; therefore they avoided this topic during prenatal consultation. Gynecologists were aware of the fact that bupropion and varenicline are contra-indicated during pregnancy and although they knew that NRT could be used safely during pregnancy, they did not recommend it.

\section{Theme 3: The image of "the smoking pregnant woman"}

Participants had a negative image of "the smoking pregnant woman": a low educated woman living with a smoking partner and "bad examples" in their history, such as smoking during a previous pregnancy without visible or immediate problems for the baby or the mother, which makes them minimalize their smoking habit.

She told me that her neighbour smoked twenty-five cigarettes every day and that she had a baby weighing over four kilograms. Yes, that is what she told me! And what can I do, how can I convince her, she was right. (Midwife 5)

This image does not fit with perceptions of the participants of a "pregnant woman": a woman who follows life style advice immediately, in order to give birth to a healthy baby. Hence, a minority of the participants believed that smoking related pregnancy complications have to be attributed to the responsibility of the woman herself. Some gynecologists even believed that these women should not be rewarded with additional attention or consultation time. Other participants believed that they need extra ultrasounds in order to examine the fetal growth, which implies extra costs for the couple and the society.

Participants believed that addiction, ignorance, stress, (complex) social problems and a lack of support of the partner and peers are barriers to attempts to cease smoking.

Most midwives and gynecologists did not believe that there are acceptable situations in which it is better for pregnant women to continue smoking, even in stressful situations. Others had a different opinion and advised to reduce daily consumption of cigarettes instead of quitting. 
Table 1

Categorization matrix based on the interview guide and the 5 A's framework in smoking cessation counseling and perceived barriers.

Theme 1: Basic knowledge regarding fetal and maternal $\quad$ Focus

risks associated with smoking during pregnancy

Fetus/child (M)
Woman and fetus/child (G)

List of risks:IUGR, LBW, placental problems, SIDS

Fertility problems, stillbirth (M-teachers, G)

Early menopause, lung diseases, cancer, premature aging of the skin, irritable or lazy baby, long term risks for the child $(\mathrm{G})$

Uncertainty about some risks, such as preeclampsia, hypertension and malformations (M) Importance of smoking prevention, not only during pregnancy (society issue)

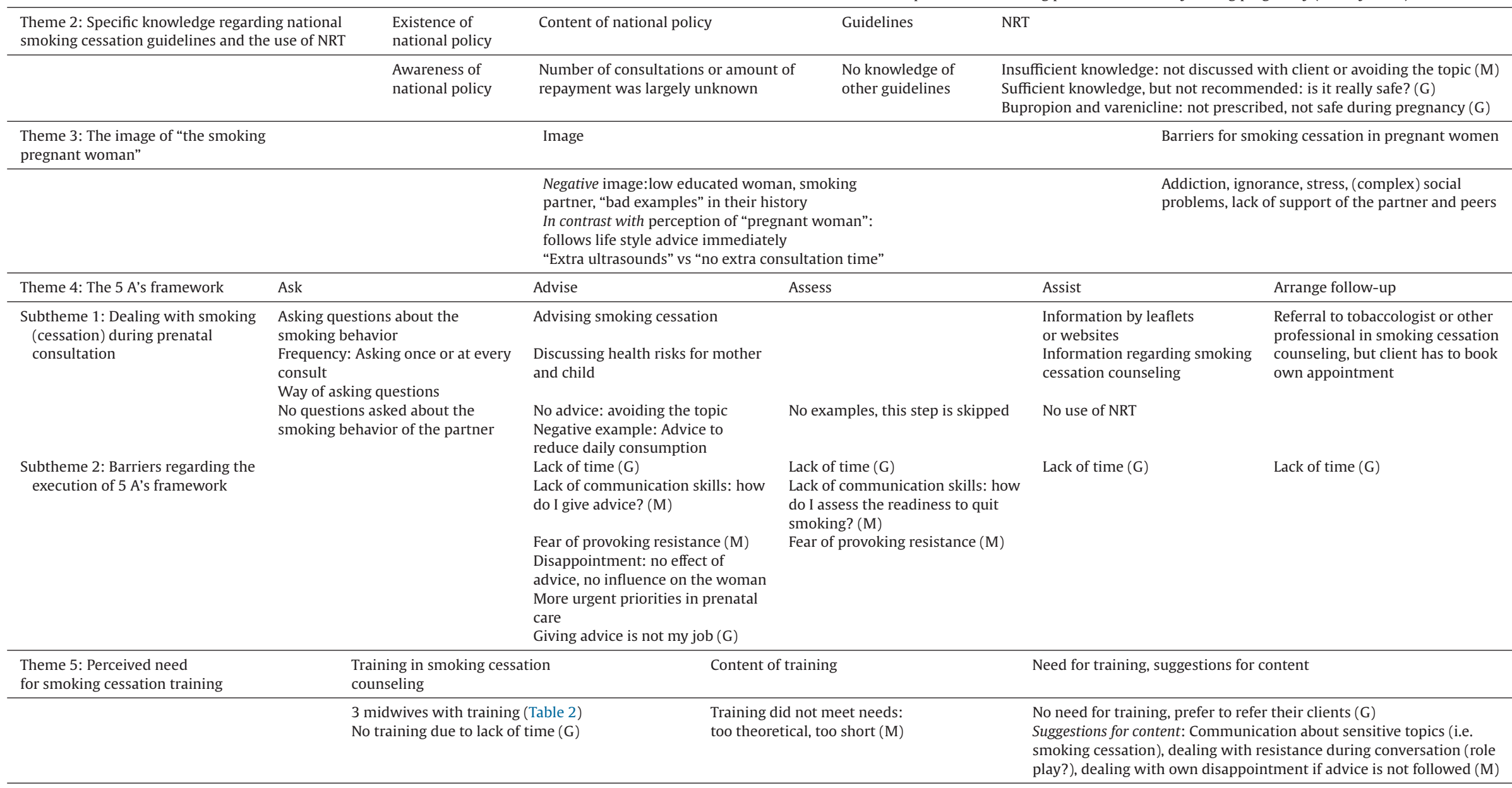

The answers are provided by both occupational groups, unless otherwise specified: midwives (M) or gynecologists (G).

play?), dealing with own disappointment if advice is not followed (M) 
Table 2

Characteristics of the participants.

\begin{tabular}{|c|c|c|c|c|}
\hline Number & $\begin{array}{l}\text { Midwife (M) or } \\
\text { gynecologist }(G)\end{array}$ & $\begin{array}{l}\text { Years of work } \\
\text { experience }\end{array}$ & Training in smoking cessation skills & Additional information \\
\hline 1 & G & 5 & & \\
\hline 2 & G & 7 & & $\begin{array}{l}\text { Stopped smoking more than } 10 \text { years ago, smoked for } \\
\text { two years }\end{array}$ \\
\hline 3 & G & 18 & & \\
\hline 4 & G & 6 & & \\
\hline 5 & M & 18 & $\begin{array}{l}\text { Attended a theoretical training in smoking cessation } \\
\text { skills of } 4 \text { hours }\end{array}$ & \\
\hline 6 & M & 2 & & \\
\hline 7 & M & 25 & $\begin{array}{l}\text { Attended training in smoking cessation skills of several } \\
\text { days. Scientific interest in the topic }\end{array}$ & $\begin{array}{l}\text { Stopped smoking more than } 20 \text { years ago, smoked for } \\
6 \text { months } \\
\text { Teacher }\end{array}$ \\
\hline 8 & M & 23 & & Work experience in developing countries \\
\hline 9 & M & 5 & & \\
\hline 10 & M & 7 & $\begin{array}{l}\text { Training in and experience with the use of the Minimal } \\
\text { Intervention Strategy (MIS) for smoking cessation in } \\
\text { prenatal care }\end{array}$ & Worked for 4 years in the Netherlands \\
\hline 11 & G & 3 & & Teacher \\
\hline 12 & M & 7 & & Teacher, worked for 2 years in the Netherlands \\
\hline 13 & $\mathrm{G}^{*}$ & 33 & & Teacher \\
\hline 14 & M & 30 & & \\
\hline 15 & M & 4 & & \\
\hline 16 & $G^{*}$ & 16 & & \\
\hline 17 & G & 15 & & \\
\hline
\end{tabular}

* Male participant.

When she can't stop smoking, I tell her to reduce the number of cigarettes to an absolute minimum. (...) Less than three cigarettes a day, in which case she is not considered to be a smoker any longer. (Gynaecologist 4)

Theme 4: The 5A's framework in smoking cessation counseling and perceived barriers

Subtheme 4.1: Dealing with smoking (cessation) during prenatal consultation The 5A's method of smoking cessation [3] was used as a framework to analyze the practice of the participants:

- Ask: All participants asked questions about the smoking status and daily consumption of their clients during the first visit and documented it in the medical record. Most midwives and some gynecologists asked the questions again during the following visits. The smoking status of the partner was not questioned.

I ask: "Do you smoke?". When she answers "Yes", then I want to know how much she smokes. I try to get insight in her reality, on the condition that she tells the truth of course. (...) I write the answers down in the medical record. (...) During the next consultation I ask if she has cut down her daily consumption. (Midwife 7)

- Advise: Most participants felt it was their duty to provide smoking cessation advice, but admitted that there are often other more urgent priorities in prenatal care, such as giving information about different ways of giving birth, pain relief and breastfeeding. Especially gynecologists expressed lack of time. One gynecologist thought that she was overqualified and that giving life style advice, including smoking cessation advice, belonged to the tasks of a tobaccologist or general practitioner.

I don't have the time. I am not the kind of person who wants to spend half an hour to motivate smoking cessation. I think that I am too highly qualified. That's not my job, I have too many other things to do. I want to refer them [smokers] to a specialist. (Gynaecologist 4)

Most participants advised smoking cessation, some advised to reduce the daily consumption, especially in stressful situations.
I think that if the woman gets too much stressed about the fact that it is forbidden to smoke, then the only thing you can say, is: "Alright, you can smoke a few cigarettes a day." I try to motivate her to smoke less than ten cigarettes, if possible less than five cigarettes a day. (Gynaecologist 3)

Risk factors associated with smoking during pregnancy were discussed with the woman in order to convince her to quit. Midwives admitted that they lack communication skills to talk about a sensitive topic like smoking and smoking cessation during pregnancy; they feared provoking resistance or not having any influence on the woman's behavior.

Lack of self-confidence and knowledge is visible, so my message about smoking cessation is not strong enough, the client doesn't listen and then I feel like I can do nothing to influence her decision. (Midwife 5)

I try to start a conversation about smoking behaviour, but when I feel that it [the conversation] is blocked and I get the opposite effect, then I will be very careful. I know that they will not stop smoking and that I am not able to do something about it. I don't want to chase them away so that they drop out of prenatal care. (Midwife 14)

- Assess: Participants skipped this step during prenatal consultation. After asking questions about the smoking behavior they immediately gave cessation advice without assessing if the woman was ready to quit smoking.

- Assist: Several participants used leaflets to support or replace their advice or referred to websites that discuss smoking cessation and different ways of counseling. NRT is not recommended.

- Arrange follow up visits: Three independent midwives referred to a general practitioner or a tobaccologist. Most gynecologists referred to a general practitioner, a tobaccologist or a psychologist working in the same hospital. All referring participants were not sure that the referral had any effect since the woman herself had to make the appointment(s) with the tobaccologist. For most women this barrier would be too high, participants thought. 
The results as a whole demonstrate that the participants have insufficient knowledge of effective health education methods, in particular regarding smoking cessation.

Subtheme 4.2: Barriers regarding the execution of 5 A's framework Participants were aware of the fact that asking questions about smoking behavior should lead them to an action, but immediately they mentioned different barriers that hindered them from taking action. Because of a lack of time, a lack of communication skills and fear of resistance they sometimes barely discuss or avoid the topic. Some participants expressed their disappointment regarding the poor effect of their smoking cessation advice. Therefore, they were reluctant to assess the smoking behavior because they felt that it was a "waste of their precious consultation time, because the smoker didn't quit anyway (gynaecologist 16)".

\section{Theme 5: Perceived need for smoking cessation training}

None of the gynecologists attended smoking cessation training due to their busy schedule. Most of them believed that it was better to refer the client to e.g. a tobaccologist than to attend a training session.

Three midwives attended some kind of training and two of them even expressed a need for more extensive training to provide them with a theoretical background about the risks of smoking during pregnancy as well as the skills to communicate about sensitive topics like smoking cessation, to deal with resistance and to conduct motivational interviewing, if possible by using role play. Some participants would like a testimony of an ex-smoker and some suggestions on how to deal with their own disappointment if the woman refuses to follow their advice.

\section{Discussion}

The objectives of our study were (1) to explore knowledge, beliefs and practice among midwives and gynecologists concerning smoking cessation several years after the implementation of a smoking cessation policy for pregnant women and their partners and (2) to examine if midwives and gynecologists in Flanders do have a role in smoking cessation in pregnant women.

All participants knew that smoking during pregnancy can cause severe health problems in (pregnant) women and babies. Despite this general opinion, there was a difference in the focus of midwives and gynecologists regarding these risks. Midwives were focused on fetal and neonatal risks since contacts are limited to pregnancy and postpartum. Risks for the pregnant woman herself were less known, thought of and rarely discussed with their clients. Gynecologists also have contact with women during nonpregnancy related consultations. Therefore, they focused on risks for both woman and fetus.

Most participants believed that knowledge of the health risks is the most important motivation for smoking cessation. Therefore, risks were listed during the first consultation and with this information participants expected women to quit. However, it has been shown that information alone is not sufficient for behavioral change; the health risks of smoking are well known and yet 30\% of the population continues to smoke [21].

The number of consultations and the amount of reimbursement of the national policy was largely unknown. For example, half of the participants thought that the national policy provided in free smoking cessation counseling. Hence, they gave the wrong information to their clients. Gynecologists and midwives should be better informed about the content of the national smoking cessation policy for pregnant women, or the pregnant women themselves should be reached with relevant information on smoking cessation in an effective way. This includes also promoting referral to a tobaccologist.
The knowledge regarding NRT, especially of midwives, was insufficient and thus NRT was not recommended. In Flanders NRT is over-the-counter medication. If the woman does not inform the pharmacist about her pregnancy, she can buy the product without specific information regarding the use and the dose of NRT during pregnancy. NRT is the only pharmacotherapy for smoking cessation that has been tested in RCTs conducted in pregnancy.

There were no statistically significant differences in rates of miscarriage, stillbirth, premature birth, low birth weight, admissions to neonatal intensive care or neonatal death between NRT or control groups, but further research regarding efficacy and safety is needed [22].

Participants had a negative image of "the smoking pregnant woman": a low educated woman living with a smoking partner and "bad examples" in their history. This image does not fit with the ideal image of the participants of a "pregnant woman": a woman who follows life style advice immediately, in order to give birth to a healthy baby. It could be possible that these prejudices hinder a conversation about smoking cessation. At the time of the interview none of the participants smoked, this also could make it more difficult to understand why a pregnant woman cannot or would not stop smoking.

All participants asked questions about the smoking status and the daily consumption. Midwife 7, who attended a more extensive training in smoking cessation, and midwife 10, with experience in MIS in prenatal care, also asked how long the client smoked, what brand and on which occasion she smoked, which led to a more profound insight in her smoking behavior. By asking the right questions it is possible to gather extra information, hence the right arguments for that specific woman that can be used to motivate her smoking cessation.

The smoking status of the partner was not questioned and passive smoking was not a topic of conversation. Given the health problems related to passive smoking [23], this topic needs special attention as well.

Several participants offered an information leaflet or referred to a website to support the oral information or as a replacement of the information in case of lack of time. Leaflets are useful as supplementary communication to inform, educate and advise people about health issues. However, when leaflets are given without oral smoking cessation advice, they have less effect [21].

In line with previous observations [6], the most important barriers for giving smoking cessation advice were lack of time, lack of communication skills in sensitive topics such as smoking cessation, and dealing with resistance. Most gynecologists believed that a conversation about the smoking behavior would take too much time, time they do not have in their opinion during a standard prenatal consultation of 10-15 minutes. Midwives mentioned several times that they did not know how to start a conversation without provoking resistance or without "chasing the woman away". Their experiences with these conversations were negative, so they discussed the topic superficially, hoping that the woman would get the message. Even midwife 5, who attended a short theoretical training about smoking cessation during pregnancy, still felt she lacked the appropriate skills.

None of the gynecologists attended a training in smoking cessation and most of them were not willing to do so. They preferred to refer the woman. Three midwives attended a training and even wanted to be trained more. However in this study there were no important differences in dealing with smoking cessation between trained and non-trained midwives. This may suggest that the duration and content of the training did not meet the needs. Midwives reported that most were too short, too theoretical and did not provide participants with the right skills to communicate about a sensitive topic such as smoking. 
"Ask", "Advice" and to a lesser extent "Assist" of the 5 A's framework were implemented in smoking cessation communication, which is similar to previous studies [3]. Although gynecologists preferred to refer their clients, referral to a tobaccologist is rare and when a woman is referred, she seldom makes an appointment, according to the participants. This might be explained by the fact that the gynecologist or the midwife is someone the woman knows and trusts, a tobaccologist is in almost all cases a stranger to them. Also the fact that they did not assess the woman's readiness to quit may hinder making the appointment.

There are two possible suggestions to help smoking pregnant women. A first strategy would be that there is someone within the obstetric team trained in giving smoking cessation advice and is seen as a confidant by the pregnant woman [24]. Since gynecologists expressed mostly time pressure as a barrier during their prenatal consultation, it could be considered to organize more shared consultations with a trained midwife. The midwife can provide prenatal care combined with life style advice, such as smoking cessation advice, and build a partnership with the woman [24,25]. A second and possibly more effective strategy in Flanders is to use an abbreviated version of the $5 \mathrm{~A}$ 's framework, more specifically the AARmethod: (1) Ask questions about the smoking behavior; (2) deliver brief Advice to quit smoking and determine the readiness and motivation to quit; and (3) Refer to specialized smoking cessation counseling, i.e. by a tobaccologist or a trained midwife [26]. Motivation may fluctuate over time or from one situation to another, which means that motivation can be influenced by searching for the right arguments for each particular client. The technique of motivational interviewing (MI) can be used to initiate a conversation about smoking, to explore and resolve uncertainties about smoking cessation and to motivate them to make a quit attempt. By using this technique an aggressive or confrontational approach is avoided and self-belief of the client is encouraged [14,27]. It would be recommendable that health care providers are trained in using MI in order to avoid resistance in clients and to enhance their own selfconfidence in discussing sensitive topics. When they assess an increased motivation of the woman to quit smoking, she can be referred to a tobaccologist. This also ensures a separation between prenatal care and smoking cessation counseling so that fear of clients dropping out of prenatal care is avoided.

\section{Limitations}

A possible limitation is the number of participants involved in the study. Only eight gynecologists and nine midwives agreed to participate, despite the fact that all registered gynecologists and independent midwives in Flanders received an invitation and a reminder. This may indicate that only health care providers with special interest in the topic agreed to participate.

A second limitation is the fact that qualitative studies are contextual, which means that the results should be related to the context of the study. This study focused on gynecologists and midwives performing prenatal consultations in Flanders. This does not imply that these findings have no meaning in other contexts, but that they must be interpreted in relation to the other context.

\section{Conclusions}

Participants had a negative image of "the smoking pregnant woman": a low educated woman living with a smoking partner and "bad examples" in their history. It could be possible that these prejudices hinder a conversation about smoking cessation.

The most important barriers reported to providing smoking cessation counseling are lack of time, restricted communication skills and fear of provoking resistance. Even trained midwives experience these barriers and have doubts about their competencies in giving smoking cessation advice. Gynecologists seem not interested in training regarding smoking cessation and prefer to refer their clients.

The following two possible suggestions to help smoking pregnant women should be explored:

1 Training in smoking cessation counseling of a team member who is seen as a confidant by the pregnant woman. This could be a trained midwife, who can provide prenatal care combined smoking cessation advice.

2 A possibly more effective strategy in Flanders is to use an abbreviated version of the 5 A's framework, more specifically the AAR-method. The role of the midwife and gynecologist is then limited to asking questions about smoking behavior, providing brief advise, determining the readiness to quit and referring clients to specialized smoking cessation counseling.

Further research should focus on the implementation of the AARmethod in order to increase the number of pregnant women who stop smoking.

\section{Conflict of interest}

The authors do not have any financial and personal relationships with other people or organizations that could inappropriately influence or bias their work.

\section{Acknowledgements}

The authors would like to thank all midwives and gynecologists who participated in this study for their time and open communication and Kathleen Temmerman, RM, MSC, for transcribing several interviews.

\section{References}

[1] Everett-Murphy K, Paijmans J, Steyn K, Matthews C, Emmelin M, Peterson Z. Scolders, carers or friends: South African midwives' contrasting styles of communication when discussing smoking cessation with pregnant women. Midwifery 2011;27:517-24.

[2] Flemming K, Graham H, Heirs M, Fox D, Sowden A. Smoking in pregnancy: a systematic review of qualitative research of women who commence pregnancy as smokers. J Adv Nurs 2012;69:1023-36.

[3] Chang J, Alexander S, Holland C, Arnold R, Landsittel D, Tulsky A, et al. Smoking is bad for babies: obstetric care providers' use of best practice smoking cessation counseling techniques. Am J Health Promot 2013:27:170-6.

[4] Bull L. Smoking cessation intervention with pregnant women and new parents (part 2): a focus group study of health visitors and midwives working in the UK. J Neonatal Nurs 2007;13:179-85.

[5] Price J, Jordan T, Dake J. Perceptions and use of smoking cessation in nurse-midwives' practice. J Midwifery Womens Health 2006;51:208-15.

[6] Herberts C, Sykes C. Midwives' perceptions of providing stop-smoking advice and pregnant smokers' perceptions of stop-smoking services within the same deprived area of London. J Midwifery Womens Health 2012;57:6773.

[7] Abatemarco D, Steinberg M, Delneveo C. Midwives' knowledge, perceptions, beliefs and practice supports regarding tobacco dependence treatment. J Midwifery Womens Health 2007;52:451-7.

[8] Everett K, Odendaal H, Steyn K. Doctors' attitudes and practices regarding smoking cessation during pregnancy. S Afr Med J 2005:95:350-4

[9] Petersen Z, Nilsson M, Everett K, Emmelin M. Possibilities for transparency and trust in communication between midwives and pregnant women: the case of smoking. Midwifery 2009:25:382-91.

[10] Röske K, Hannöver W, Thyrian J, John U, Hannich H. Smoking cessation counseling for pregnant and postpartum women among midwives, gynaecologists and paediatricians in Germany. Int J Environ Res Public Health 2009;6:96-107.

[11] Thyrian J, Hannöver W, Röske K, Scherbarth S, Hapke U, John U. Midwives' attitudes to counseling women about their smoking behaviour during pregnancy and postpartum. Midwifery 2006;22:32-9.

[12] Bull L, Whitehead E. Smoking cessation intervention with pregnant women and new parents: a survey of health visitors, midwives and practice nurses. J Neonatal Nurs 2006;12:209-15. 
[13] Treasure J. Motivational interviewing. Adv Psychiatr Treat 2004;10:331-7.

[14] Lai D, Cahill K, Qin Y, Tang J. Motivational interviewing for smoking cessation. Cochrane Database Syst Rev 2010;(1):Art. No.: CD006936.

[15] Hoppenbrouwers K, Roelants M, Guérin C, Van Leeuwen K, Desoete A, Wiersema J Sociaaleconomische indicatoren en perinatale gezondheidseffecten van gedwongen blootstelling van een Vlaamse geboortecohorte aan tabaksrook tijdens de zwangerschap en in de eerste levensweken (in samenwerking met Kind en Gezin), SWVG Feiten en cijfers (Socio-economic indicators and perinatal health effects of forced exposure of a Flemish birth cohort to tobacco smoke during pregnancy and in the first weeks after birth (in collaboration with Child \& Family), 2011, SWVG Facts and figures); 2011.

[16] $16^{\text {th }}$ of February 2010, Belga, <www.standaard.be $>$; [accessed 20.02.10]

[17] De Gauquier K, Remacle A Prenatale zorg in België in 2005. Studie van het Intermutualistisch Agentschap Brussel. (Prenatal Care in Belgium in 2005. Study of the Intermutualistisch Agentschap Brussels); 2007.

[18] De Gauquier K, Remacle A, Lucet C Prenatale zorg in België in 2002. Studie van het Intermutualistisch Agentschap Brussel. (Prenatal Care in Belgium in 2002. Study of the Intermutualistisch Agentschap Brussels); 2006.

[19] Ceuppens A, Di Zinno T, Guillaume J, Regueras N Le suivi prénatal en Belgique en 2010. Comparison avec les résultats 2005. Une étude de l'Agence Intermutualiste. (Prenatal Care in Belgium in 2010. Comparison with the results of 2005. Study of the Intermutualistisch Agentschap Brussels); 2013.
[20] Elo S, Kyngäs H. The qualitative content analysis process. J Adv Nurs 2008;62:107-15.

[21] Naidoo J, Wills J. Foundations for health promotion. 3rd ed. Edinburgh, London, New York, Oxford, Philadelphia, St Louis, Sidney, Toronto: Ballière Tindall Elsevier; 2009.

[22] Coleman T, Chamberlain C, Davey MA, Cooper SE, Leonardi-Bee J. Pharmacological interventions for promoting smoking cessation during pregnancy. Cochrane Database Syst Rev 2012;(9):Art. No.: CD010078.

[23] Higashida Y, Ohashi K. Reduction of tobacco smoke exposure for pregnant passive smokers using feedback of urinary cotinine test results. J Obstet Gynaecol Res 2014;40:1015-22.

[24] Ebert L, van der Riet P, Fahy K. What do midwives need to understand/know about smoking in pregnancy? Women Birth 2009;22:35-40.

[25] International Confederation of Midwives, Essential competencies for basic midwifery practice, <http://www.internationalmidwives.org >; 2010.

[26] Tobacco Cessation Leadership Network. Help Your Colleagues: Ask, Advise, Refer Model. Retrieved from https://www.myctb.org/wst/healthylawrence/livewell/ TobaccoFreeLiving/American\%20Lung\%20Association\%20Advocates\%20 Toolbox/Module-4/Ask-Advise-Refer-Model.pdf; 2010

[27] Everett-Murphy K, Paijmans J, Steyn K, Matthews C, Emmelin M, Peterson Z. Scolders, carers or friends: South African midwives' contrasting styles of communication when discussing smoking cessation with pregnant women. Midwifery 2011;(4):517-24. 